The new journal is edited by Dr. Eva Crane, director of the Bee Research Association, with Dr. James Simpson of the Bee Department at Rothamsted Experimental Station acting as associate oditor. They are assisted by an international Editorial Advisory Board of nine members well known in different fields of bee research. The stated policy of the journal is to cover all aspects of subjects relating to bees (Apis and other bees), and also research on methods and equipment for the management of bees and their products. This is carried out satisfactorily in the first issue.

The general presentation of the journal is acceptable, since it has clear print and tables, and diagrams of a suitable size. All the papers in the first issue are concisely written, which perhaps emphasizes the impression that the proportion of short contributions is rather high. However, this might have been largely remedicd if two of them (by W. P. Nye and M. W. Pedersen; and B. Furgala) had been placed in a separate section for preliminary reports, since the first gives rather inconclusive results of two experiments on the relationship between nectar sugar concentration and alfalfa pollination, while the second promises more data and a fuller discussion of the subject - the residual activity of fumagillin in rolation to Nosema infections-in another paper. It is also a little difficult to see why two short papers by M. V. Smith have not been combined, although the editors may be following a poliey of separating deseriptions of apparatus from experimental work where possible. In this case, one paper is a report of experiments culminating in the successful transportation of honey-bee brood from Britain to the United States by air, with the object of importing new stock into the United States, and the other describes the portable incubator used for this purpose. Another minor point is that one wishes that some diagrams had been included in the very detailed and clear description of the pre-pupal and pupal ecdyses of the honey-bee by S. Cameron Jay, but no other matters concerning the actual presentation of this journal call for any comment.
As stated earlier, the scope of the first issue is wide, and the remaining papers cover the genetics, behaviour and biology of bees, and the antibactericidal properties of honey. The latter paper is a brief one by $\mathrm{D}$. Adcock on the destructive effect of catalase on the "inhibine" and peroxide values of various honeys. J. Woyke has a paper on the hatchability of "lethal" eggs of honey-bees, in which he reports fairly normal hatching rates in these eggs but rapid removal of the young larvæ by the workers. There is a very useful deseription of a controlled environment flight room for the study of behaviour inside and outside the hive, together with records for pollen collecting activities in the room at different light intensities (W. P. $\mathrm{Nye}$ ). J. B. Free shows that geraniol, although it is the principal volatile constituent of honey-bee scent gland secretion, is not nearly so attractive as scent-gland odour itself, and therefore concludes that the attractiveness of the latter depends partly on other constituents.

In a paper describing the events following construction of the queen cell in honey-bee colonies N. E. Gary and R. A. Morse give results demonstrating the extreme variability which exists in the rearing and replacement of queens; it is apparent that swarming or supersedure does not necessarily follow queen rearing. The longest paper is by Cécile Plateaux-Quénu on the biology of Halictus marginatus, which she claims to have a type of social organization previously unknown in insects. Workers and queen are morphologically indistinguishable, and both are capable of mating, although for most of the developmental cycle of the colony (5-6 years) they have no contact with the males. Various aspects of social life in this bee are considered, and although more numerical data could have been desired, it is an interesting description.

In conclusion, it can be said that the first issue of the Journal of Apicultural Research augurs well for the future, and that, once it has become properly established, it should be a valuable publication.

M. Delia Allen

\title{
SPECTROGRAPHIC ANALYSIS AS AN AID TO DIESEL ENGINE MAINTENANCE
}

\begin{abstract}
$\mathrm{T}$ HE replacement of the steam engine as the traditional motive power by Diesel locomotives has now become familiar on British Railways, and in fact in many other countries this transition is all but complete. The economic arguments in favour of this change are that the Diesel unit offers to the railways greater efficiency, lower fuel costs and greater availability. Technically these advantages may to some extent be offset by the much greater complexity of the Diesel as compared with the steam locomotive, and problems of maintensuce of the complicated machinery involved in the oil-driven engines are constantly arising. The risk of accidental damage to Diesel mechanisms, involving sudden breakdowns with their attendant disruption of operating railway schedules, equally heavy repair costs, is very real. One way of control in prevention of these contingencies has been found by routine spectrographic analysis of Diesel engine crankcase oil. An informative account of this procedure is contained in the well-designed house organ of the British Petroleum Co., B.P. Magazine (No. 8; 1963), in an illustrated article by J. K. Lock and P. R. Mason, respectively, of the lubricants and analytical sections of the B.P. Research Centre, Sunbury-on-Thames, where such spectrographic facilities are available as are similarly developed at the Company's Centre at Melbourne, Australia.

As with other internal combustion engines, normal wear in a Diesel engine over a period of time occasions entrance
\end{abstract}

in the crankcase oil charge of minute metal particles. In this case, however, there is little if any sedimentation or sludge as ordinarily understood; the metal particles are so small that they are measured in parts per million; conventional methods of chemical analysis are not applicable to their identification because of their low concentration. In such cases spectrographic technique supplies the answer. "If regular samples of the crankcase oil charge are taken and analysed for these metal contents, a normal pattern of wear can be recognized for any one engine, performing a specified duty. If, however, a fault develops in the engine that causes an increase in wear, this pattern of wear is disturbed and can be recognized at an early date." The authors continue: ". . . the value of the service is that it permits small faults to be recognized and rectified, whereas if these faults were allowed to progress without rectification, serious damage and an expensive repair bill might ensue". Normally, nine elements are determined spectrographically in these crankcase oils: iron, copper, lead, tin, silicon, chromium, boron, aluminium and silver. The significance of the determination of each of these elements in the oil and their interpretation in terms of Diesel engine wear and tear constitute an expert enquiry. This article conveys impressively the substance of the technique involved.

H. B. MilneR 